\title{
Microstructure of Semi-Solid 6063 Alloy Fabricated by Radial Forging Combined with Unidirectional Compression Recrystallization and Partial Melting Process
}

\author{
Yongfei Wang ${ }^{1, \mathrm{a},}$ Shengdun Zhao ${ }^{1}$ and Xuzhe Zhao ${ }^{2}$ \\ ${ }^{1}$ School of Mechanical Engineering, Xi'an Jiaotong University, Xi'an 710049, China \\ ${ }^{2}$ Purdue Institute of Technology, Purdue University, West Lafayette 47906, USA
}

\begin{abstract}
Radial forging combined with unidirectional compression (RFCUM) is introduced in recrystallization and partial melting (RAP) to fabricate semi-solid 6063 aluminum alloy, which can be defined as a process of RFCUM-RAP. In this study, the microstructures of semi-solid 6063 alloy prepared by semi-solid isothermal treatment (SSIT) and RFCUM-RAP processes are investigated. The results show that, the solid grains of semi-solid alloy prepared by SSIT are large and irregular. However, solid grains of semi-solid billet prepared by RFCUC-RAP are fine and spherical. Additionally, during RFCUC-RAP process, with the increase of isothermal holding time, the shape of solid grain is more and more spherical, but the size of solid grain is gradually increased. To obtain ideal semi-solid microstructure, the optimal isothermal holding temperature and time are $630^{\circ} \mathrm{C}$ and $5 \sim 10 \mathrm{~min}$, respectively.
\end{abstract}

\section{Introduction}

Semi-solid metal process (SSMP) developed by Spencer and co-workers has been widely studied in recent years, which is an effective near-net-shape forming process [1-4]. Compared with conventional casting and forging processes, it offers significant advantages, such as easy forming, long die life, good microstructure and good mechanical properties [5]. The key requirement of SSMP process is that the semi-solid billet with fine and spherical solid grains uniformly distributed in the liquid phase. To prepare ideal semi-solid microstructures, many methods have been developed, such as, mechanical and electromagnetic stirring [6,7], cooling slope [8], mechanical vibration [9], strain-induced melt activation (SIMA) [2, 10], and recrystallization and partial melting (RAP) [11]. Among these methods, RAP process consists of warm deformation and semi-solid isothermal treatment (SSIT) is a promising method, because that many alloys are always supplied in the deformed state.

Al-Mg-Si based aluminum alloys, such as 6063 alloy, are widely employed in automotive and aerospace industries due to their high mechanical properties. However, they are currently machined from the wrought state with much waste. Therefore, there is a strong driving force to use SSMP process to form this alloy. In this study, RFCUM is introduced in RAP to fabricate semi-solid 6063 alloy, the microstructures of semi-solid 6063 alloy prepared by semi-solid isothermal treatment (SSIT) and RFCUM-RAP process are investigated. Moreover, the optimal SSIT parameters for ideal semisolid microstructures are also explored.

\footnotetext{
${ }^{\mathrm{a}}$ Corresponding author : yongfeio@126.com
} 


\section{Experimental procedure}

The as-extruded 6063 wrought aluminum alloy bar $(\varnothing 120 \mathrm{~mm} \times 180 \mathrm{~mm})$ was used as experimental material, and it consisted of 0.93 wt.\% Mg, 0.61 wt.\% Si, 0.26 wt.\% Fe, 0.19 wt.\% Cu, 0.15 wt.\% Mn, $0.05 \mathrm{wt} . \% \mathrm{Ti}, 0.11 \mathrm{wt} \% \mathrm{Cr}$ and balance of $\mathrm{Al}$. The solidus and liquidus temperatures were $615{ }^{\circ} \mathrm{C}$ and $655^{\circ} \mathrm{C}$, respectively, which were determined by differential scanning calorimeter (DSC) method. Moreover, the solid fraction versus temperature curve obtained from DSC result is shown in Figure. 1.

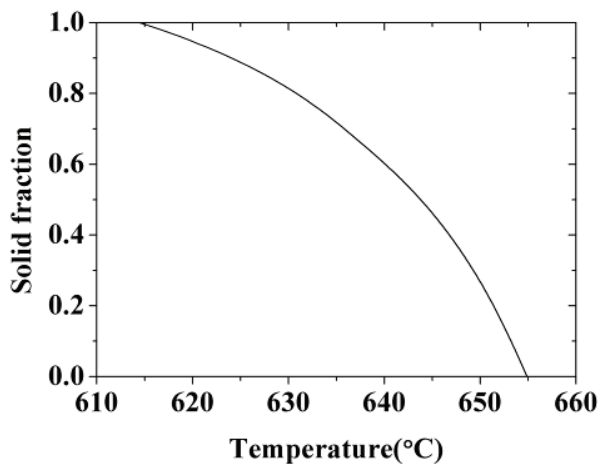

Figure 1. Liquid fraction versus temperature curve derived from DSC result.

Figure. 2 shows the schematic illustration of RFCUC-RAP process. As shown in Figure. 2, the RFCUC-RAP process could be divided into two steps: the deformation and the SSIT steps. The deformation process of 6063 alloy consists of radial forging and unidirectional compression. First, the as-received 6063 bar after preheating at $300{ }^{\circ} \mathrm{C}$ for $90 \mathrm{~min}$ was radial forged with $70 \%$ ARR and quenched in water. The ARR can be defined as area reduction ratio, which is calculated by the following equation: $\mathrm{ARR}=(\mathrm{A} 0-\mathrm{A} 1) / \mathrm{A} 0$, where $\mathrm{A} 0$ and $\mathrm{A} 1$ are the initial and final cross sectional area of the alloy bar, respectively. Second, the as-forged material with a diameter of $10 \mathrm{~mm}$ and a length of $15 \mathrm{~mm}$ was cut along the radial forging direction for unidirectional compression. The compression ratio was $80 \%$, and the compression direction was the same with the radial forging direction. During the SSIT process, the samples were treated at $630{ }^{\circ} \mathrm{C}$ for $1 \sim 20 \mathrm{~min}$ in a resistance furnace. After the SSIT process, the samples were taken out immediately and quenched in water to obtain the semi-solid microstructures. In addition, in order to investigate the effects of SSIT process on the microstructure of 6063 alloy, the samples cut from the as-received alloy were treated at $630{ }^{\circ} \mathrm{C}$ for $5 \sim 20 \mathrm{~min}$, and then quenched in water.
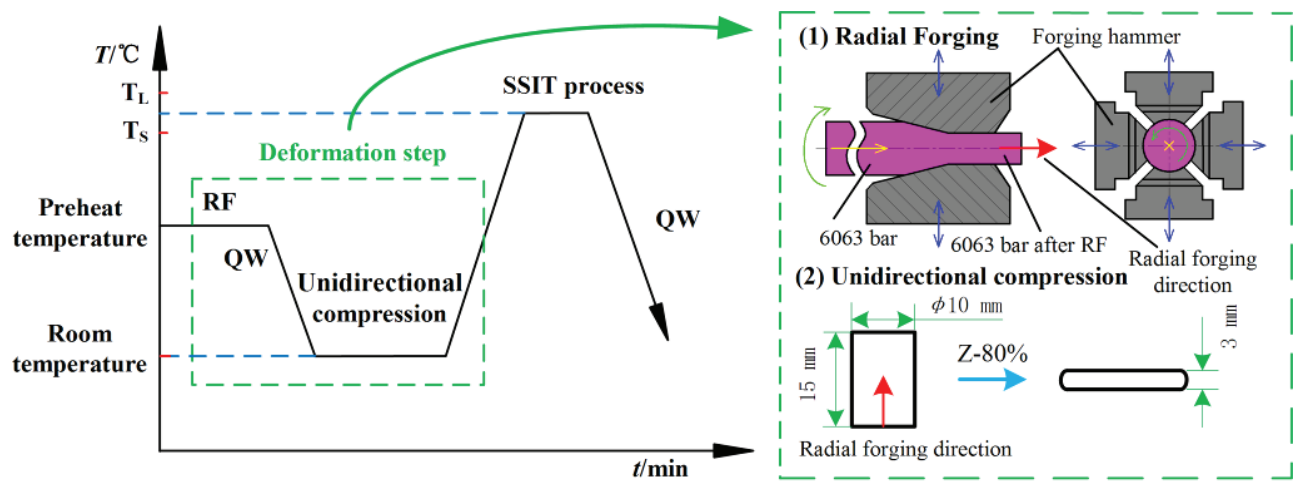

Figure 2. Schematic illustration of RFCUMRAP process.

The samples after SSIT process of as-received and RFCUC deformed alloys were ground and polished, and then etched with an aqueous solution of 5\% HF. The metallographic observation was carried out by optical microscopy (OM). The average grain size (D) and shape factor (F) of solid 
grains were measured by image analysis software (Image-Pro Plus 6.0), and calculated in each case by Eqs. (1) and (2) [12]:

$$
\begin{aligned}
& \mathrm{D}=\frac{\sum_{N=1}^{N} \sqrt{4 A / \pi}}{N} \\
& \mathrm{~F}=\frac{\sum_{N=1}^{N} 4 \pi A / P^{2}}{N}
\end{aligned}
$$

Where $\mathrm{A}, \mathrm{N}$ and $\mathrm{P}$ are area, the number and perimeter of solid grains, respectively. If $\mathrm{F}$ is gradually closed to 1 , solid grains will be more and more spherical.

\section{Results and discussion}

\subsection{Microstructure of as-received and RFCUC-deformed alloy}

Figure. 3 shows the microstructure of as-received and RFCUC-deformed alloy. As shown in Figure. $3(\mathrm{~A})$, the microstructure is typical of extrusion alloy with fibrous grains and intermetallic particles aligned in the extrusion direction. The microstructural feature of RFCUC deformed alloy shown in Figure. 3(B) is similar to that of the as-received alloy. However, it is evident that the deformation degree shown in Figure. 3(B) is higher than that in Figure. 3(A), resulting from the additive deformation of RFCUC process. Additionally, there is no evidence of recrystallization across can be seen in Figure. 3(B), possibly owing to the low deformation temperature [13].
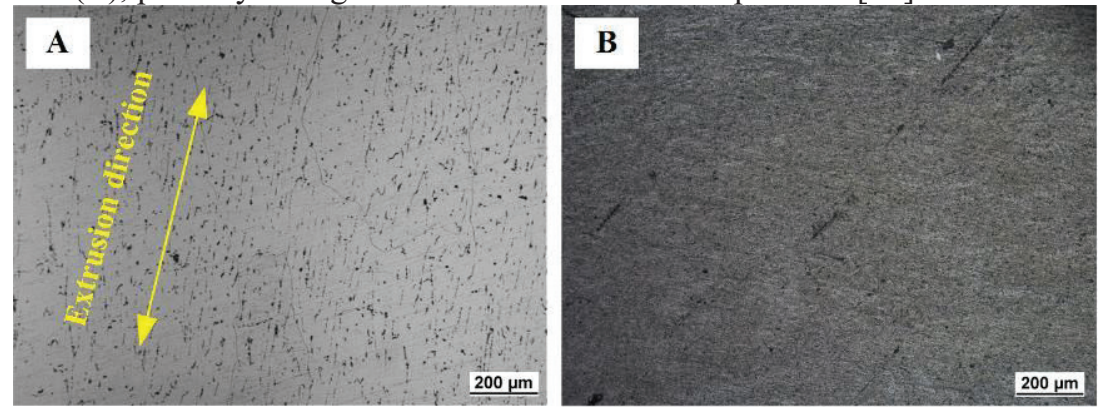

Figure 3. Microstructure of 6063 alloy: (A) as-received alloy, (B) RFCUC-deformed alloy.

\subsection{Microstructure of as-received alloy after SSIT}

Figure. 4 shows the microstructure of as-received alloy after SSIT at $630{ }^{\circ} \mathrm{C}$ for $5 \sim 20 \mathrm{~min}$. In Figure. 4(A), when the isothermal holding time is $5 \mathrm{~min}$, the liquid phase is little; the number of independent solid grain is few, and the size of solid grain is large. In Figure. 4(B), when the isothermal holding time is increased to $10 \mathrm{~min}$, the number of solid grains is increased, and the size of solid grain is decreased, indicating that the size of solid grain can be decreased at the intial stage of the SSIT process. With increasing the isothermal holding time from $15 \mathrm{~min}$ to $20 \mathrm{~min}$, the solid grains (Figure. 4(C) and (D)) become larger and more irregular than that shown in Figure. 4(A) and (B). The main reason can be explained as follows: the as-received 6063 alloy is an extrusion bar with little strain energy, which can not offer an enough driving force for recovery and recrystallization during the SSIT process [14]. The optimal average grain size and shape factor of solid grains measured from Figure. 4 are about $207 \mu \mathrm{m}$ and 0.72 (Figure. 4(B)), respectively. For the SSMP process, the semi-solid billet with large and irregular solid grain will have an adverse effect on the mechanical properties of final parts [15]. Therefore, it is obvious that the SSIT of as-received alloy is unsuitable for fabricating ideal semi-solid 6063 alloy. 

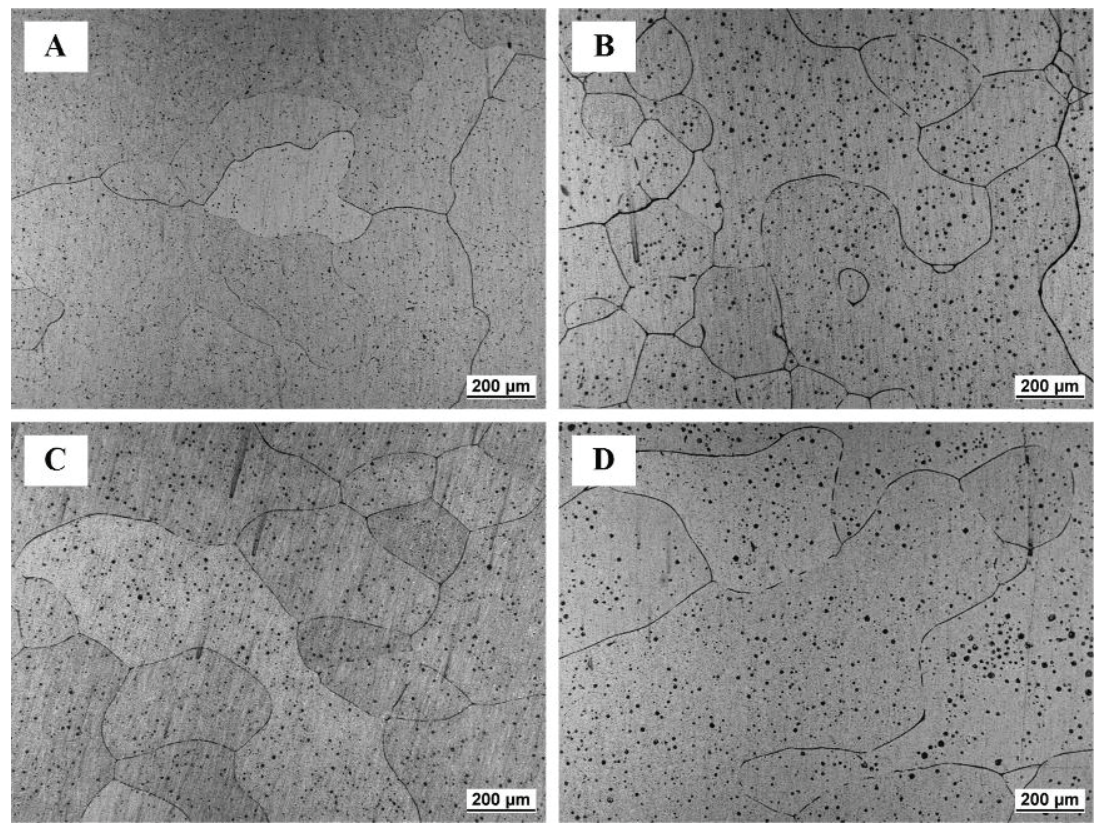

Figure 4. Microstructure of as-received alloy after SSIT at $630^{\circ} \mathrm{C}$ for different times: (A) $5 \mathrm{~min}$, (B) $10 \mathrm{~min}$, (C) $15 \mathrm{~min}$ and (D) $20 \mathrm{~min}$.

\subsection{Microstructure of RFCUC-deformed alloy after SSIT}

Figure. 5 shows the microstructure of RFCUC-deformed alloy after SSIT at $630{ }^{\circ} \mathrm{C}$ for $1 \sim 20 \mathrm{~min}$. As shown in Figure. 5 (A), when the isothermal holding time is $1 \mathrm{~min}$, the deformed direction of alloy are gradually disappeared, and some recrystallized grains can be found in the microstructure (marked with A1). As indicated in Figure. 5(B), when the isothermal holding time is $3 \mathrm{~min}$, the recrystallization phenomenon fully occurs. At the same time, the boundaries of solid grains start to melt. The liquid phase starts to appear at the grain boundaries and triple points between grains (marked with B1). As shown in Figure. 5(C), when the isothermal holding time is increased to $5 \mathrm{~min}$, the liquid is gradually increased because of the melting process; the majority of solid grains are separated by liquid film, and the grain size is small. As shown in Figure. 5 (D) (F), when the isothermal holding time is prolonged from $10 \mathrm{~min}$ to $20 \mathrm{~min}$, the liquid film is more and more thicker due to the increase of liquid phase, the grain size is gradually increased and the spheroidization degree of grain is improved. Moreover, some excessive larger solid grains (marked with F1 and F2) can be found in Figure. 5(F), which is attributed to the grain coalescence.

Figure. 6 shows the variations of the average grain size and shape factor of solid grains with the isothermal holding time from the quantitative analysis of the microstructure shown in Figure. 5. It should be noted that it is difficult to measure the solid grains shown in Figure. 5(A) and (B), because there are no obvious solid grains shown in Figure. 5(A) and the solid grains shown in Figure. 5(B) are connected together. As shown in Figure. 6, with the increase of isothermal holding time, the average grain size and shape factor of solid grains are gradually increased.

The microstructural evolution of alloy produced by the RFCUC-RAP process can be described as follows: during the RFCUC process of alloy, the strain energy is stored in the forms of dislocations, providing the driving force for recovery and recrystallization [16]. Therefore, during the initial stage of SSIT process, in order to reduce the free energy, the dislocation will climb and cross slip, leading to the occurrence of recovery and recrystallization (Figure. 5(A)). With the increase of isothermal holding time, liquid phase starts to appear (marked with B1) because that the isothermal holding temperature $\left(630^{\circ} \mathrm{C}\right)$ is higher than the solidus temperature. Moreover, the liquid penetrates the grain boundaries 

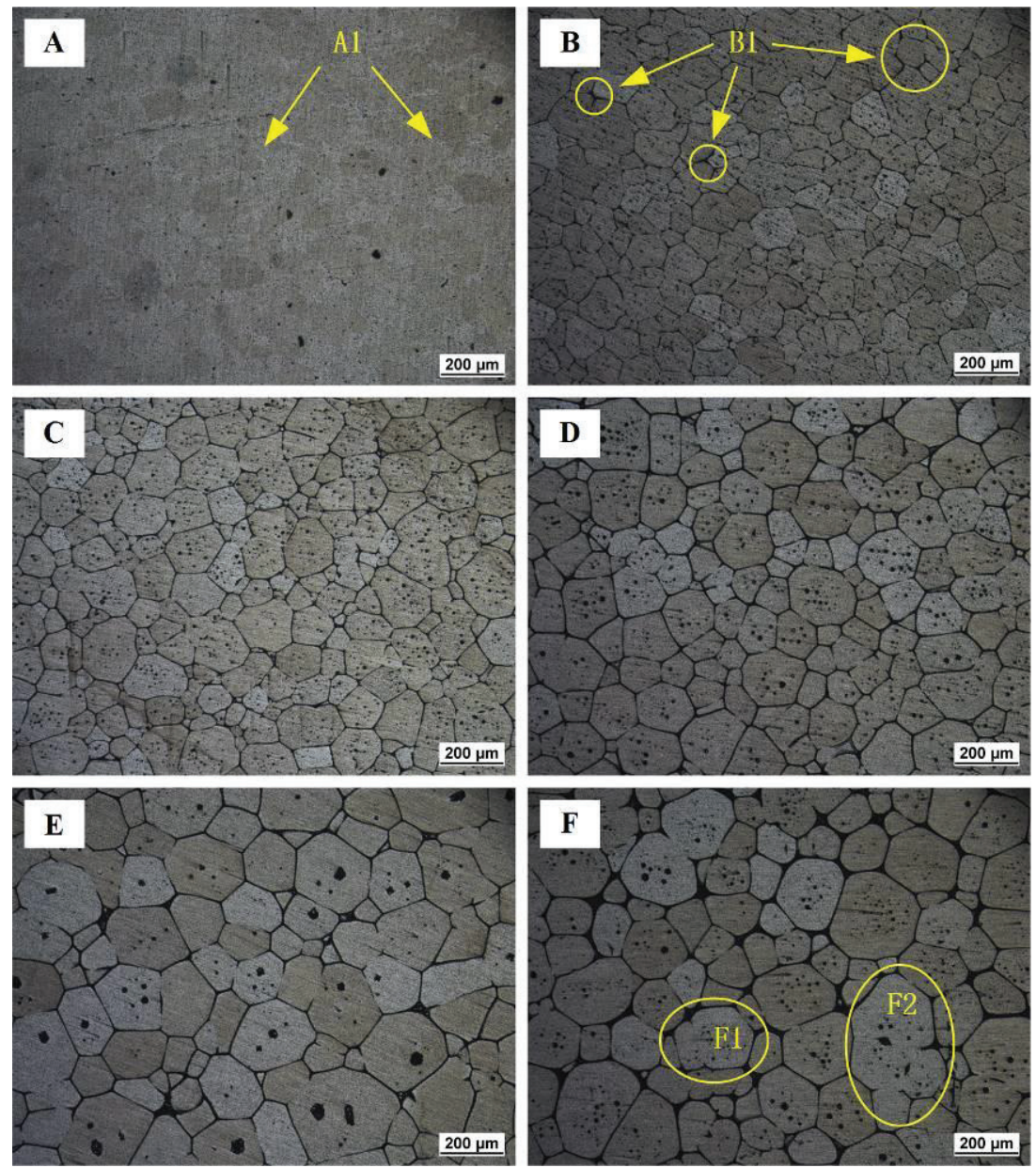

Figure 5. Microstructure of RFCUM-deformed alloy after SSIT at $630{ }^{\circ} \mathrm{C}$ for different times: (A) 1 min, (B) 3 min, (C) 5 min, (D) 10 min, (E) 15 min and, (F) 20 min.

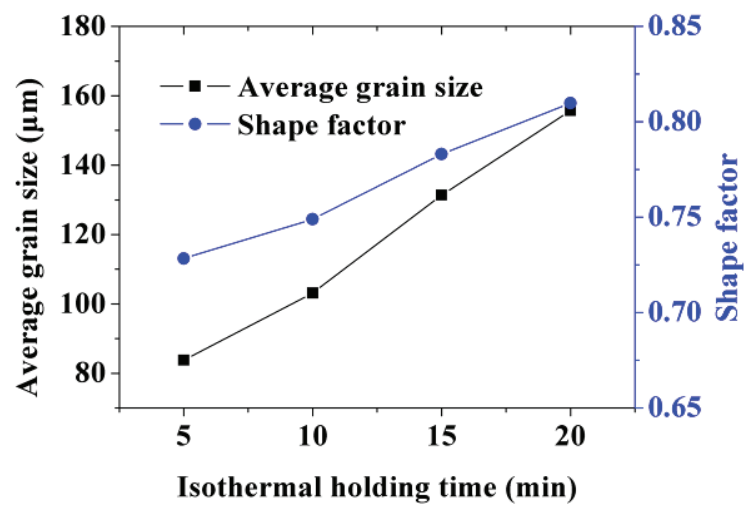

Figure 6. Variations of the average grain size and shape factor with the isothermal holding time

when the grain boundary energy is greater than twice the solid-liquid interface energy, which will lead to the formation of liquid film and fine solid grains (Figure. 5(C)). With further increasing the isothermal holding time, the grain coalescence occurs gradually, and then the average grain size is increased. At the same time, owing to the effect of interface curvature, the spheroidization degree of 
solid grain is improved (Figure. 5(D) $\sim(E)$ ). When the isothermal holding time is long enough to make the majority of solid grains separated with each other (Figure. 5(F)), the Ostwald ripening also starts to play a role on grain coarsening. From the results of Figure. 4 6, it can be concluded that, compared with the SSIT of as-received 6063 alloy, the RFCUC-RAP process in this study is an effective method to produce ideal semi-solid billets. The optimal isothermal holding temperature and time are $630{ }^{\circ} \mathrm{C}$ and $5 \sim 10 \mathrm{~min}$, respectively; the average grain size is $83.80 \sim 103.15 \mu \mathrm{m}$ and the shape factor is $0.73 \sim 0.75$.

\section{Conclusion}

In this study, the microstructures of semi-solid $6063 \mathrm{Al}$ alloy fabricated by semi-solid isothermal treatment (SSIT) and RFCUM-RAP process are investigated. The main conclusions are summarized as follows:

(1) Compared with the large and irregular solid grains produced by the SSIT process of asreceived 6063 alloy, the RFCUC-RAP process is an effective method to obtain the ideal semi-solid billets with fine and spherical solid grains.

(2) For preparing the ideal semi-solid billet, the optimal isothermal holding temperature and time are $630{ }^{\circ} \mathrm{C}$ and $5 \sim 10 \mathrm{~min}$, respectively. Furthermore, the average grain size is $83.80 \sim 103.15 \mu \mathrm{m}$ and the shape factor is $0.73 \sim 0.75$.

\section{Acknowledgments}

The authors are grateful to the National Natural Science Foundation of China (grant no. 51675414 and 51405378) and the Xi'an Science and Technology Plan Projects (grant no. CXY1514 (1)) for funding this study.

\section{References}

1. A. Bolouri, M. Shahmiri, C.G. Kang, J. Mater. Sci 47, 3544 (2012)

2. Y. Xu, L. Hu, J. Jia, B. Xu, Mater. Charact 118, 309 (2016)

3. Q. Chen, Z.D. Zhao, G. Chen, B. Wang, J. Alloy. Compd 632, 190 (2015)

4. D.B. Spencer, R. Mehrabian, M.C. Flemings, Metall. Mater. Trans. B 3, 1925 (1972)

5. Y.F. Wang, S.D. Zhao, C.Y. Zhang, R.G. Guan, Mater. Trans 58, 176 (2017)

6. R. Haghayeghi, E.J. Zoqui, A. Halvaee, M. Emamy, J. Mater. Process. Tech 169, 382 (2005)

7. P. Kaur, D.K. Dwivedi, P.M. Pathak, Int. J. Adv. Manuf. Tech 63, 415 (2012)

8. N.V. Thuong, H. Zuhailawati, A.A. Seman, T.D. Huy, B.K. Dhindaw, J. Mater. Eng. Perform 24, 2018 (2015)

9. Y. Murakami, K. Miwa, M. Kito, Mater. Trans 57, 168 (2016)

10. B. Binesh, M. Aghaie-Khafri, Mater. Charact 106, 390 (2015)

11. Y. Meng, S. Sugiyama, J. Yanagimoto, J. Mater. Process. Tech 214, 87 (2014)

12. J.F. Jiang, Y. Wang, H.V. Atkinson, Mater. Charact 90, 52 (2014)

13. H.V. Atkinson, K. Burke, G. Vaneetveld, Mat. Sci. Eng. A 490, 266 (2008)

14. G.H. Yan, S.D. Zhao, S.Q. Ma, H.T. Shou, Mater. Charact 69, 45 (2012)

15. J.F. Jiang, Z.M. Du, Y. Wang, S.J. Luo, Solid State Phenom 271, 29 (2015)

16. B. Binesh, M. Aghaie-Khafri, Metals 6, 42 (2016) 